Elias Thomé Saliba

Historiador, professor associado do Departamento de História da USP e Autor de As

Utopias Românticas.

\title{
CABRIÃO: HUMOR E PARÓDIA POLÍTICA ${ }^{1}$
}

Semanário satirizava os costumes, a política e o clero, na São Paulo do final do século XIX

$\mathrm{P}$

irracento, amolador, impertinente - assim era Cabrion, um personagem dos Mistérios de Paris, de Eugène Sue - uma história típica do gênero conhecido como folhetim, assim designado inicialmente porque não ocupava a página inteira dos jornais. Precedendo certo sensacionalismo que só viria mais tarde, com a reportagem policial, o folhetim começou a aparecer nos jornais semanais que eram, na metade do século 19, ainda excessivamente doutrinários, cheios de artigos pesados e bem diferentes do noticiário temperado, leve e variado dos jornais mais modernos. Ocupando um espaço demarcado ao pé das páginas dos jornais, não raro com linhas pontilhadas para o leitor recortar e colecionar, o folhetim foi, sem dúvida, o maior instrumento de divulgação, no século 19 , de romances, novelas e, até mesmo, de ensaios, para um público mais amplo e variado.

Foi mais ou menos assim com o Cabrião, um semanário humorístico publicado em São Paulo durante os anos de 1866 e 1867 . Respondendo à intrínseca vocação paródica do humor brasileiro, o nome escolhido foi facilmente reconhecido pelo seleto público leitor da época, pois o famoso folhetim de Eugène Sue já havia sido publicado no Brasil vinte anos atrás. Cabrião não era um folhetim. mas possuía seções que guardavam uma certa semelhança do gênero, adotando narrativas que terminavam, invariavelmente, como o clássico "continua no número seguinte", mantendo algum suspense no leitor, como "A História do Cabrião", "Sobre a romã encantada", "O penúltimo cavaco" etc. - colunas que se repetiam em vários números. A difusa estrutura folhetinesca também pode ser vista na prósimilar. São Paulo: Unesp/Imprensa Oficial, 408p. Este artigo foi veiculado no jornal O Estado de S. Paulo, em 12 de junho de 2001. p. D-7. (N. Ed.) 
pria dupla de calungas desenhada por Agostini - Cabriāo - impertinente e gozador - e Pipelet - sistemático, regrado e ortodoxo - que se repetiam em todos os números, comentando a vida política na província ou retratando episódios da Guerra do Paraguai. Eram oito páginas, sendo quatro de textos e quatro de caricaluras e desenhos - as pitorescas litografias de Ângelo Agostini - que convidavam os leitores para cabrionar, literalmente, para brincar ou encher a paciência dos outros, induzindo-os a uma espécie de lúdica cumplicidade na celebração da trapaça e da ambiguiidade.

Ambiguidade muito mais presente no humor visual, já que foi exatamente uma

\section{CABRIÃO}

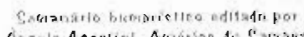

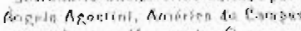

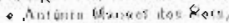
1200.1807

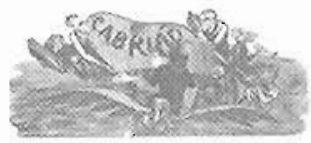

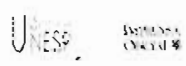

Edição tac-similar de Cabriāo foi organizada por Dého Freure dos Santos

referencia à morte que gerou um processo contra o jornal, por "atentar contra a moral e a religião": uma cena que mostrava um regabofe entre morlos e vivos alcoolizados, confraternizando-se em frente ao Cemiłério da Consolação. O processo, articulado pela faç̧ão calólica dos conservadores, acabou não dando em nada, mas recebeu uma lerina resposta visual: uma caricatura de página inteira, com um grande baile de esqueletos e 0 Cabriāo no trono, sob o dístico inspirador do comediante, Ridendo castigat mores ("Rindo criticamos us costumes"), Os exageros dos redatores em parodiar Os Mistérios de Paris aparecem no renitente anticlericalismo das charges e das anedotas, sobretudo aquelas destinadas a satirizar o poder de jesuítas e clérigos já que, numa época onde não havia autonomia da Igreja em relação ao Estado -, a política e os negócios não eram incompatíveis com o sacerdócio. Na verdade, o anti-jesuitismo de Sue vinha a calhar, transformando-se em instrumento para o jornal satirizar o estado de coisas existente na província, estigmatizando sobretudo os políticos conservadores - aqueles para os quais, na curta definição de Nabuco, "a conservação principal era a do governo em suas próprías mãos".

\section{CIRITICA À GUERRA DO PARAGUAI}

Edilado pelos jovens Américo de Campos, Angelo Agostini ${ }^{2}$ e Antônio Manoel dos Reis, o pequeno tablóide filiava-se à linhagem dos liberais do Império que, nestes anos, já começavam a administrar dissiclências e cisões (incluindo as dos abolícionistas) em suas próprias fileiras. O Cabriăo pode

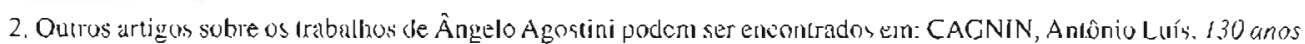
do Diabo Coxo. O primeiro pariódico de São Paulo (1864-1994). Comunicação \& Éducação. Sũo Páulo CCA-ECAUSP/Modcrua, II. I, sel./der. 1994. p. 27-31. Yellon: Ked, o molecrue que nấr ers umarelo. Comunicação \& Educaçño. São Paulo: CCA-ECA-USP/Moderna. n. 7, sel /der 1996. p. I07-108 (N, Ed.) 
mesmo ser considerado uma espécie de antecessor da fundação dos "Clubes Radicais" que, nas diversas províncias. reuniram as facções de liberais insatisteitos com as intervençôes do Imperador, particularmente com aquela última, em 1868, que dissolveu o gabinete liberal e manteve Caxias no comando do exército.

Muitas das sátiras e ironias do Cabrião possuem estas peculiaridades políticas, com chaves mais difíceis para o leitor decifrar.

Grande parte do humor do semanário dirigia-se para a moda, os costumes e os comportamentos cotidianos, além de referências irônicas sempre atuais - à guena do Paraguai a aos perversos efeitos do recrutamento miliúar sobre a população.

A moda leminina - com os famosos sonetos dedicados à saia balão; a festá do entrudo, com a condenação dos lançadores de água que provocavam defluxos e resfriadus nos foliôes; assim como os impagáveis Mandamentos do homem de tretas, Decálogo de um bềbado ou Regras de Economia são lemas recorrentes nas divertidas páginas do Cabrião. Algumas vezes envergonhado - tapando o rosto com as mãos para não ver a corrupção na venda de lítulos monárquicos - noulras vezes abobalhado, com um monte de medalhas e condecorações alfinetándo seu peito nu
- o Brasil é sempre representado, pelo desenho notável de Agostini, como um pobre índjo - um Tibiriçá humilhado, transformado num lítere nas mãos de Pipelet ou do próprio Cabrião.

Mas não há nada de agressivo e nem de ressentimento explícito no humor de Cabriäo. Ainda sob forte impacto de um Iluminismo civilizador, que procurava fazer proselitisno de alguns códigos de comportamento, o humor desta época acreditava, ainda, que o riso persuasivo era, por princípio, um riso decente e não ofensivo. Quando convidava os leitores para cabrionar, o pequeno jornal parecia insistir que o simples ato de compartilhar o riso era até mais importante do que o conteúdo especílico ou o impacto imediato de qualquer piada ou caricatura. Rir junto significava participar de uma cultura comum, uma forma de comunicação sobre assuntos de interesse mútuo. O humor ajudava assim, anda que timidamente, a levantar interdiçōes, a construir um espaço público - um campo onde poderiam ser discutidos todos os tipos de idéias, fossem elas políticas, sociais ou morais.

O humor não tem essência. Fó sempre uma construção, uma invenção cultural e histórica.

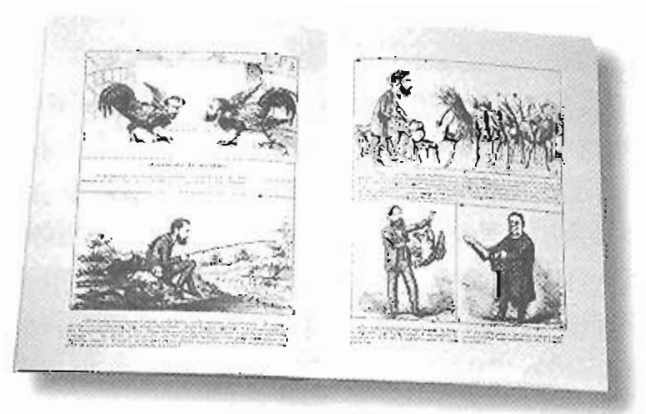

Cabriāo, um jornal de crílica e sátira à política e aos costumes da época. 
Com uma introdução enciclopédica de Délio Freire dos Santos, o leitor pode ter em mãos um registro precioso e divertido, de uma publicação que catalisou, ao mesmo tempo, o prestígio do folhetim entre o seleto circuito de leitores da época e o clima de ebulição política, que começou a jogar mais lenha na fogueira do caldeirão do fim do Império.

Resumo: $\mathrm{O}$ artigo trata da publicação do livro com os fac-símiles das ediçōes do semanário humorístico Cabrião, jornal que circulou na cidade de São Paulo entre os anos de 1866 e 1867.0 autor retoma as origens do jornal, inspirado no personagem Cabrion de Os mistérios de Paris, folhetim de Eugène Sue; e analisa seu perfil humoristico e paródico dos costumes, da política e do clero da cidade. O Cabrião foi editado por Ângelo Agostini, Américo de Campos e Antônio Manoel dos Reis por um curto período, mas representou um momento importante da construção das linguagens verbal e visual do humorismo brasileiro.

Palavras-chave: Cabrião, humor, jornal, paródia, semanário humorístico

\begin{tabular}{c}
\hline O Cabrião representou um \\
momento importante $-\mathrm{e}$ \\
pouquíssimo conhecido - da \\
construção de uma possível \\
linguagem. verbal e visual, do \\
humorismo brasileiro.
\end{tabular}

(Cabriāo: humor and political parody)

Abstract. The article deals with the publication of a book containing facsimiles of the editions of the Cabrião humor seminar. The Cabriāo was a newspaper that circulated in the city of São Paulo between 1866 and 1867. The author brings up the newspaper's origins, inspired in the Cabrion character, from The Mysteries of Paris, a daily chapter of a newspaper serial published by Eugène Sue; and analyses its humoristic and parodic profile of customs, of politics and of the city's clergymen. The Cabrião was edited by Ângelo Agostini, Américo de Campos and Antônio Manoel dos Reis for a short period, but represented an important moment in the construction of Brazilian humor's verbal and visual languages.

Key words: Cabrião, humor, newspaper, parody, humor seminar 